substitutions in the $\alpha_{1} \beta_{2}$ contact regions show diminished haem-haem interactions. Finally, reagents which are believed to affect the $\beta$ chain structure in the $a_{1} \beta_{2}$ contact region abolish cooperative effects.

This difference of opinion over whether the functional unit of haemoglobin is a dimer or a tetramer underlines the greatest disappointment of the determination of the structure of oxyhaemoglobin. Unlike the X-ray crystallographic determinations of the structure of enzymes, such as lysozyme and ribonuclease, the elucidation of the structure of oxyhaemoglobin has not made it immediately obvious how haemoglobin works, how it binds oxygen and how haem-haem interactions are achieved. Perhaps the answer will emerge when the Cambridge group has completed the model of deoxyhaemoglobin on which it is now working. Certainly there should be a rich harvest to be gathered from the attempts now likely to be made at the interpretation of the detailed properties of particular variants of the haemoglobin molecule in terms of the molecular structure which has now become available. The efforts of the past thirty years should soon begin to bring rewards. As Dr Perutz said recently, "What we have done is merely the anatomy at the atomic level. Now it is necessary to advance to the physio$\log \mathrm{y} . "$

\section{Plant Pathology Progresses}

THe yield of a crop is often lower than it could be because of infection with viruses, although there are no visible symptoms of disease. Greater losses result from widespread infection with "mild" viruses than from localized outbreaks of virulent ones, and so one of the preoccupations of plant pathologists is the production of virus free stock. At East Malling Research Station heat treatment-at $37^{\circ} \mathrm{C}$ for 3-4 weeks-has been used to produce the strawberry Cambridge Favourite which showed a 60 per cent increase in marketable yield in a field trial. Virus free stock has been issued annually since 1955 and this variety now accounts for 63 per cent of the acreage of strawberries in Britain. Tree fruits can be treated similarly and "mother trees" free of all known viruses are now being issued.

The few diseases of fruit which are caused by bacteria have proved very difficult to control. Bacterial canker of plum and cherry is caused by Pseudomonas morsprunorum, which enters the stem through leaf scars in the autumn and spreads to produce the brown cankers in which the bacteria finally die in the spring. These cankers cause considerable losses, especially among young leaves. Many bactericides including streptomycin have been tested at East Malling, but nothing as efficient as Bordeaux mixture (copper sulphate and lime) has been found. Blossom blight of pear, also caused by a pseudomonad, is less important but can sometimes cause severe damage.

Within the morphologically similar group of pseudomonads eausing these diseases three host specific types have been distinguished by growing the bacteria on special culture media. Type 1 is restricted to pear, type 2 to plum and cherry and type 3 to myrobalan, the cherry plum. Type 2 bacteria from plum and cherry show different sensitivities to various bacteriophages, and so it seems that distinct forms of bacteria, which do not cross infect in the field, infect each of these different fruits.

Apple scab, causcd by the fungus Venturia inaequalis, is one of the world's most important plant diseases. The wind borne ascospores, which infect the trees in spring, are produced after the fungus has overwintered in fallen leaves. Control methods have so far been confined to between eight and fifteen sprayings of fungicide each year, to maintain a protective film on the leaves and fruits while the ascospores are being discharged.

At East Malling a large number of compounds have been tested in a search for a fungicide that will kill Venturia before the ascospores can be produced. Mercuric compounds sprayed on to the leaves have this effect, but they are costly and involve health risks. Urea which is much cheaper and safer has been found to have the same effect on the fungus. Leaves collected and dipped in 5 per cent urea in the autumn, produced no ascospores in the spring. Leaves collected from the orchard floor after the trees had been sprayed with urea produced few ascospores, and this was reflected in a reduced ascospore content in the atmosphere in the spring. This reduction was partly caused by earthworms, which showed a strong preference for leaves treated with urea.

Research to determine the way the urea acts has shown that it causes a change in the balance of the microbial population of the leaves. After treatment with urea, Gram negative bacteria predominate whereas on untreated leaves there are more Gram positive bacteria. The bacteria isolated from treated leaves have been found to be antagonistic towards scab fungus, and one of them produces an antibiotic against the spores of the fungus. Suppression of the fungus may therefore be caused by antagonistic bacteria, but work is continuing at East Malling in pursuit of this and other possible explanations. It is hoped that work on apple scab will lead to a relatively cheap and effective means of controlling the disease by spraying the leaves on the trees in the autumn.

\section{Pea-green Soup}

A "PEA-GREEN SOUP" is how Mr Ian Dunn, leader of the Royal Society's IBP team in East Africa, describes Lake George in Uganda. Mr Dunn was speaking at the scientific meeting of the Freshwater Biological Association a week ago where he gave a progress report of the team's work so far. The team of five is busy studying the productivity of the lake, which in a few years may be altered if there is further development along the shores of the lake--which has an extremely high gross productivity.

A part of the reason for this lies in the physical nature of the lake. It is situated right in the tropicsthe Equator in fact passes through the middle. The lake is very shallow; apart from one small area where the depth reaches $7 \mathrm{~m}$, the average depth of the water is not more than $3 \mathrm{~m}$. Other features of the lake include a high average $p \mathrm{H}$, high concentration of dissolved oxygen and high levels of phosphate, calcium, iron manganese and silica. The overall pattern which is emerging from the preliminary investigations is one of uniformity. There seem to be quite substantial diurnal variations in the biology and chemistry of the lake, but there are only small seasonal changes. The lack of much variation over the year is a reflexion of 